\title{
Household expenditure by Output Area Classification
}




\section{Background}

This chapter presents income and expenditure by Output Area Classification (OAC). The classification is designed to group together geographic areas based on a series of characteristics which are shared by these groupings. Hence areas sharing an OAC classification have characteristics in common, but may be distributed over different parts of the UK.

The aim is to provide an overview that highlights key findings from the 2009 Living Costs and Food Survey (LCF) by OAC but not a comprehensive analysis of income and expenditure. A similar chapter was included in the 2008 edition of Family Spending. The analysis was well received, so the theme is revisited in this edition. Tables showing expenditure and income by OAC groupings have been included since the 2008 edition.

There are seven categories in the highest OAC 'supergroup' classification, these are subdivided into 21 OAC groups. Most of the tables and figures in this chapter present LCF data aggregated at the OAC supergroup level, considered to be the most appropriate level at which to present the data for the purposes of an overview. In addition, presentation of some results by the lower-level OA classification provides further detail while illustrating how the characteristics of the higher groups sometimes mask differences in the lower groups.

\section{Introducing OAC}

Output Areas are the smallest geographical units used to release data from the 2001 Census. Each census agency was responsible for the creation of the OAs in their countries and there are some slight differences in the methodology employed by the different agencies. The Office for National Statistics (ONS) and Northern Ireland Statistics and Research Agency (NISRA) both adopted the ONS methodology, based upon a minimum OA size of 40 households and 100 residents. This differed somewhat from the design methodology used in Scotland, where OAs were matched more closely to the 1991 Census OAs and thus maintained a smaller minimum size of 20 households and 50 residents.

\section{Table $5.1 \quad$ Average size of OAs by census agency ${ }^{1}$}

\begin{tabular}{lrrrrr}
\hline Country & OAs & Population & Households & $\begin{array}{r}\text { Average } \\
\text { Population } \\
\text { per OA }\end{array}$ & $\begin{array}{r}\text { Average } \\
\text { Households } \\
\text { per OA }\end{array}$ \\
\hline UK & 223,060 & $58,789,154$ & $24,479,439$ & 264 & 110 \\
England and Wales & 175,434 & $52,041,916$ & $21,660,475$ & 297 & 124 \\
Scotland & 42,604 & $5,062,011$ & $2,192,246$ & 119 & 52 \\
Northern Ireland & 5,022 & $1,685,267$ & 626,718 & 336 & 125 \\
\hline
\end{tabular}

As Table 5.1 shows, 223,060 different output areas were produced from the 2001 Census data. Due to the high number of individual OAs, it was hoped that clustering groups of areas based on shared characteristics would enhance understanding of the areas and enable a clearer identification of patterns in their distribution. 
Fundamentally, the classification is used to group together geographic areas based upon a series of characteristics which are shared by the populations in these groupings. The 2001 Census was the first in which this type of classification was formulated to enhance the publication of results.

\section{Developing the Classification}

In order to be considered an official census-based National Statistic, the variables chosen to formulate the OA classification were drawn solely from the 2001 Census. As noted in the official technical report, 'the goal of the variable choice for this classification was to select the minimum possible number of variables that satisfactorily represent the main dimensions of the 2001 Census (Vickers and Rees 2005) ${ }^{2}$. After several revisions, an eventual list of 41 variables was drawn from the 2001 Census outputs. These variables were together deemed representative of five main domains within the census outputs; Demographic Structure, Household Composition, Housing, Socio-Economic status and Employment.

To develop the classification itself, the output areas were then placed in groups which were considered sufficiently similar according to the values recorded for particular census variables. This was achieved using the statistical method of cluster analysis; specifically involving the use of the kmeans clustering algorithm in the SPSS statistical package. The k-means algorithm is a very commonly used method in the geodemographics sector and is principally used to reduce the level of within-cluster variability. Initially, the whole data set of 223,060 OAs was input into the k-means algorithm to produce the first level of the cluster hierarchy, the supergroups. Subsequently, the seven clustered data sets produced for the supergroups were then each re-clustered separately to produce the middle-tier of the hierarchy, the groups. The files produced for the groups were themselves then re-clustered to produce the lowest tier of the classification, the subgroups. Table 5.2 shows the way in which the OAC groups can be mapped to the highest tier of the hierarchy, the supergroups. 


\section{Table $5.2^{3}$ Relationship of OAC supergroups to OAC groups}

\begin{tabular}{|c|c|c|}
\hline OAC Supergroup Label & OAC Group & OAC Group Label \\
\hline \multirow[t]{3}{*}{1 - Blue collar communities } & $1 \mathrm{~A}$ & Terraced blue collar \\
\hline & 1B & Younger blue collar \\
\hline & $1 \mathrm{C}$ & Older blue collar \\
\hline \multirow{2}{*}{$2-$ City living } & $2 \mathrm{~A}$ & Transient communities \\
\hline & $2 \mathrm{~B}$ & Settled in the city \\
\hline \multirow[t]{3}{*}{3 - Countryside } & $3 A$ & Village life \\
\hline & $3 B$ & Agricultural \\
\hline & $3 C$ & Accessible countryside \\
\hline \multirow[t]{4}{*}{4 - Prospering suburbs } & $4 \mathrm{~A}$ & Prospering younger families \\
\hline & $4 \mathrm{~B}$ & Prospering older families \\
\hline & $4 \mathrm{C}$ & Prospering semis \\
\hline & $4 \mathrm{D}$ & Thriving suburbs \\
\hline \multirow[t]{3}{*}{5 - Constrained by circumstances } & $5 \mathrm{~A}$ & Senior communities \\
\hline & $5 B$ & Older workers \\
\hline & $5 \mathrm{C}$ & Public housing \\
\hline \multirow[t]{4}{*}{6 - Typical traits } & $6 \mathrm{~A}$ & Settled households \\
\hline & $6 \mathrm{~B}$ & Least divergent \\
\hline & $6 \mathrm{C}$ & Young families in terraced homes \\
\hline & $6 \mathrm{D}$ & Aspiring households \\
\hline \multirow[t]{2}{*}{7 - Multicultural } & $7 A$ & Asian communities \\
\hline & 7B & Afro-Caribbean communities \\
\hline
\end{tabular}

\section{Cluster Profiling and Naming}

To complete the classification, cluster profiles were created and then given names which would clearly distinguish them from those used in other classifications. The fundamental aim of the cluster profiles was 'to create a short description, using text and visuals which expands on the cluster names but only takes a few seconds to read but which significantly expands the user's understanding of the group' (Vickers and Rees 2006) ${ }^{4}$. Table 5.3 summarises the cluster profiles. It indicates the distinctive variables which set each cluster apart from the remaining clusters, based on how far their cluster values deviate from the overall mean for those variables.

Much time was taken in producing names for the clusters and all were 'reviewed, developed and approved by a group of ONS Neighbourhood Statistics and geography specialists' (Vickers and Rees 2006) ${ }^{5}$. This was in order to ensure that the resultant labels were concise, inoffensive and reflected accurately what kinds of areas were represented by each cluster.

It is important to note that the cluster names, while carefully chosen, cannot represent all the complexity of the groups. The names should therefore be treated with caution, and not used independently of the cluster profiles. 
A considerable amount of detail on the OA classification is available on the ONS website: www.statistics.gov.uk/about/methodology by theme/area classification/oa

This includes a full technical report ${ }^{6}$ which provides a detailed explanation of the methodology underpinning the classification, as well as a significant amount of information relating to the cluster profiles.

\section{Household Expenditure by OAC}

Figure 5.1 and table 5.4 show expenditure by OAC supergroup, in total and for each of the Classification of Individual Consumption by Purpose (COICOP) categories. As might be expected, there are considerable differences in total expenditure. The supergroups with the highest expenditure are supergroups 2 (city living) and 4 (prospering suburbs), spending an average of $£ 457.90$ and $£ 454.10$ per week, respectively, followed by supergroup 3 (countryside), with expenditure of $£ 433.70$. Supergroup 5 (constrained by circumstances) showed the lowest expenditure at $£ 269.20$ followed by supergroup 1 (blue collar communities).

\section{Figure 5.1 Average weekly household expenditure by OAC supergroup 2009}

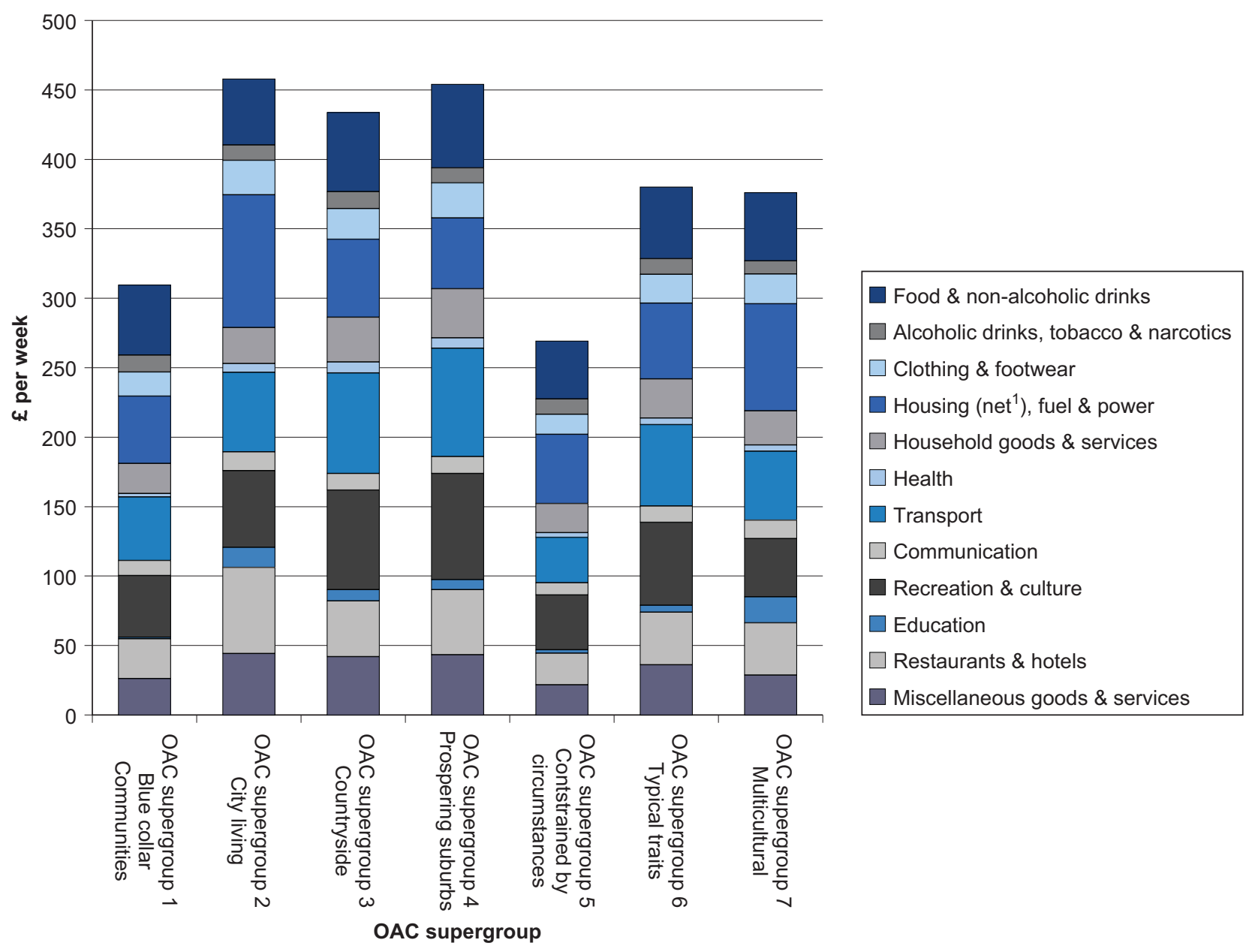

1 Excluding mortgage interest payments,council tax and Northern Ireland rates. 
The pattern of total expenditures observed for 2009 is similar to 2007 , when the analysis was first conducted. Since 2007 supergroup 2 (city living) total average weekly household expenditure has gradually risen to exhibit the largest expenditure of all OAC supergroups. Supergroup 4 (prospering suburbs) and 3 (countryside) continue to be in the top three. All other supergroups have maintained the same rank for the three-year period, with supergroup 5 (constrained by circumstances) remaining consistently the lowest.

The differences in total expenditure between supergroups can be considered in more detail by COICOP categories. High expenditure by supergroup 2, 'city living', was partially attributable to expenditure on housing, fuel and power (£95.60), which was higher than for any other group. Expenditure on housing fuel and power showed high variability between supergroups; after "city living' the next highest expenditure in this category was by supergroup 7 'multicultural' (£77.00). All other supergroups spent considerably less, with supergroup 1 (blue collar communities) spending the least at $£ 48.40$ per week.

Other categories also showed a high level of variability between supergroups. For example, transport expenditure was highest for supergroup 4 'prospering suburbs' (£77.90) and supergroup 3 'countryside' (£72.20), and lowest for supergroup 5 'constrained by circumstances' (£32.70). Spending on restaurants and hotels was almost three times as much in the highest-spending category, 'city living' (£62.20) than the lowest, 'constrained by circumstances' (£22.80).

By contrast, average weekly household expenditure for alcoholic drinks, tobacco and narcotics, health and communication showed minimal differences between OAC supergroups. This pattern is consistent with the results obtained for 2007.

When looking at data at the supergroup level (Table 5.5), it is important to note that the supergroups are high-level clusters containing thousands of individual output areas. As such, when the expenditure estimates are broken down further, to the middle tier of the cluster hierarchy (OAC groups), the supergroups can exhibit considerable internal variability for certain expenditure categories. For example, high expenditure on housing fuel and power by supergroup 2 'city living' (noted in the previous paragraph), differs for the supergroup's individual group levels. The high expenditure for this supergroup is largely driven by group 2A 'transient communities' with an average weekly expenditure of $£ 120.10$, considerably higher than group $2 B$ 'settled in the city' at $£ 82.00$. This latter figure is lower than 'Affro-Carribean communities' within the 'multicultural' supergroup (£90.00).

Expenditure on transport revealed interesting variation within supergroups. High expenditure on transport within supergroup 4 (prospering suburbs) was attributably mainly to group $4 a$ 'prospering younger families', at $£ 97.80$. Within supergroup 5 'constrained by circumstances', which showed the lowest expenditure on transport overall, expenditure was notably low among group 5a 'senior communities', at $£ 19.00$. 'Prospering younger families' also spent highly on recreation and culture (£88.60), but the second highest-spending group on this category was group 3a 'village life'(£82.10), within the 'countryside’ supergroup. 


\section{Household Income by OAC}

Table 5.6 and Figure 5.2 show average gross weekly household income by OAC supergroup. The clustering process used to create the classification did not include a direct income indicator, though it did include correlated variables such as the ownership of two or more cars, so it is interesting to see that expenditure and income follow broadly the same pattern at the supergroup level, as was the case in 2007. However, it should be noted that the survey is not designed to produce a balance sheet of income and expenditure for individual households or groups of households and as such, this comparison is only intended to provide an approximate indication of the broad similarities between the two.

\section{Figure 5.2 Average gross normal household income by OAC supergroup, 2009}

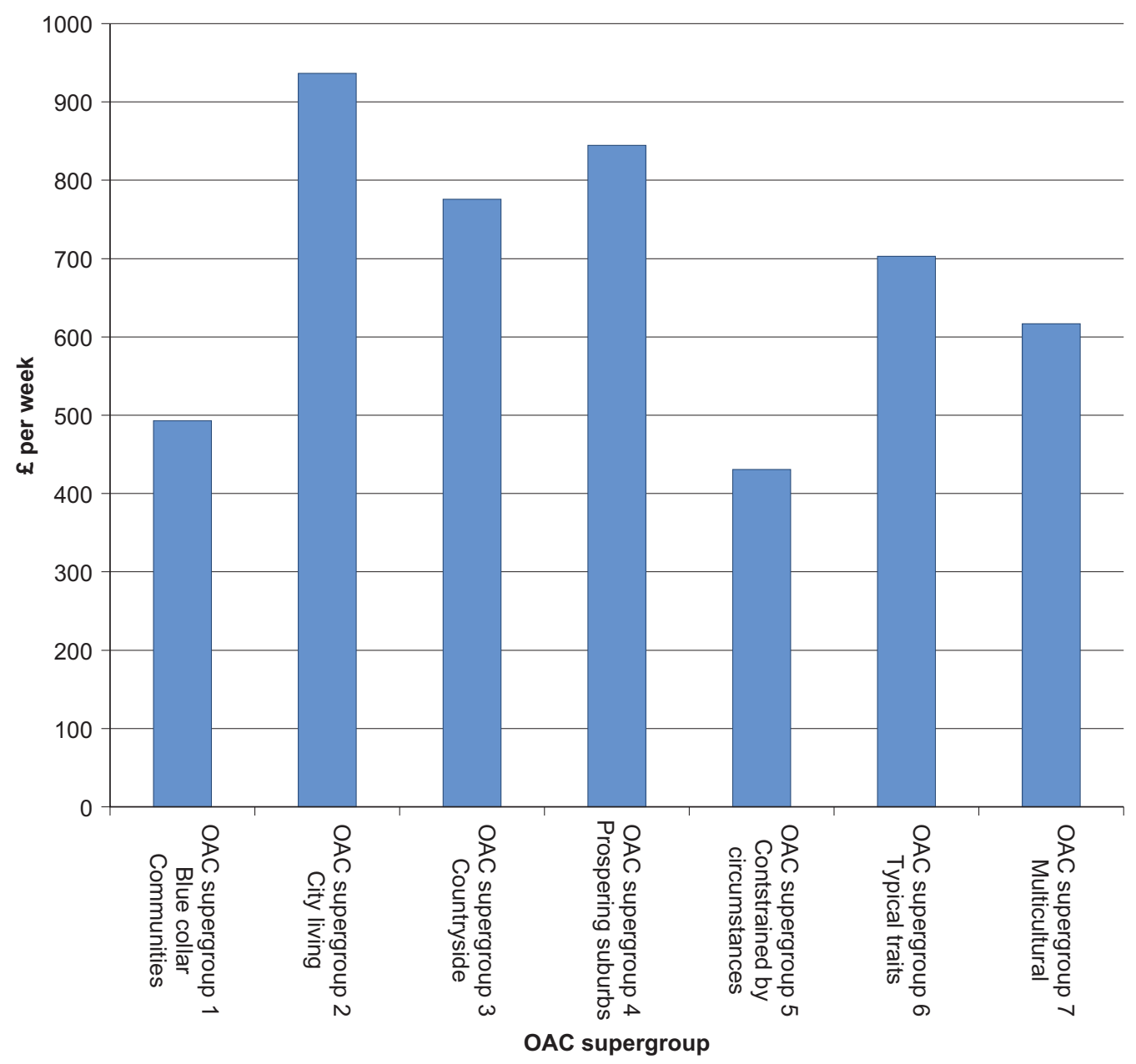

\section{Notes}

1, 3, 4 \& 5: See Vickers, D. \& Rees, P. (2006) Creating the UK National Statistics 2001 output area classification.

2 \& 6: See Vickers, D., Rees, P. \& Birkin, M. (2005) Creating the national classification of Census output areas: data, methods and results. 


\section{Table 5.3 OAC cluster profiles, supergroup level ${ }^{1}$}

\begin{tabular}{lll}
\hline OAC & $\begin{array}{l}\text { Variables with proportions above the } \\
\text { national average }\end{array}$ & $\begin{array}{l}\text { Variables with proportions below the national } \\
\text { average }\end{array}$ \\
\hline & Age 5-14 & Indian, Pakistani and Bangladeshi \\
& Lone parent households & Black \\
1 & Households with non-dependent children & Born Outside the UK \\
Blue collar & Routine/Semi-routine Employment & Rent (Private) \\
communities & Mining/Quarrying/Construction employment & FE Qualification \\
& Manufacturing Employment & Financial Intermediation Employment \\
& Retail Trade Employment & \\
& Lone parent households &
\end{tabular}

\begin{tabular}{|c|c|c|}
\hline & Age $25-44$ & Ages $0-4,5-14,25-44$ and $65+$ \\
\hline & Born Outside UK & Single Parent Household \\
\hline & Population Density & Households with non-dependent children \\
\hline & Single person household & Rooms per household \\
\hline 2 & Rent (Private) & Provide unpaid care \\
\hline \multirow[t]{5}{*}{ City living } & Flats & Economically inactive looking after family \\
\hline & No Central Heating & General employment \\
\hline & HE Qualification & \\
\hline & Students & \\
\hline & Financial Intermediation Employment & \\
\hline \multirow{8}{*}{ Countryside } & Ages 45-64 and 65+ & Indian, Pakistani and Bangladeshi \\
\hline & Detached Housing & Black \\
\hline & Rooms per Household & Population Density \\
\hline & 2+ Car Households & Single Person Household \\
\hline & Work from Home & Flats \\
\hline & Provide Unpaid Care & People Per Room \\
\hline & Agricultural Employment & Public Transport to Work \\
\hline & & Unemployment \\
\hline
\end{tabular}




\section{Table 5.3 OAC cluster profiles, supergroup level ${ }^{1}$}

\begin{tabular}{|c|c|c|}
\hline & Age 45-64 & Indian, Pakistani and Bangladeshi \\
\hline & Two adults no children & Black \\
\hline & Households with non-dependent children & Divorced/Separated \\
\hline & Detached housing & Single Person Household \\
\hline 4 & Rooms per household & Single Pensioner Households \\
\hline Prospering & $2+$ Car households & Renting Public and Private \\
\hline & Provide unpaid care & Terraced Housing \\
\hline & & Flats \\
\hline & & No Central Heating \\
\hline & & LLTI \\
\hline & & Unemployment \\
\hline & Age $65+$ & Two adults no children \\
\hline & Divorced/separated & Rent (Private) \\
\hline & Single Pensioner Households & Detached Housing \\
\hline & Lone Parent Households & Rooms per household \\
\hline 5 & Rent (Public) & HE Qualifications \\
\hline Constrained by & Flats & 2+ Car Households \\
\hline Clicuinstátices & People per Room & Work From Home \\
\hline & Routine/Semi-routine employment & \\
\hline & LLTI & \\
\hline & Unemployment & \\
\hline 6 & Work Part Time & Age $65+$ \\
\hline Typical traits & Terraced Housing & Rent (Public) \\
\hline & Ages $0-4$ and $5-15$ & Ages $45-64$ and $65+$ \\
\hline 7 & Indian, Pakistani and Bangladeshi & Single Pensioner Households \\
\hline Muliticultural & Black & Two adults No Children \\
\hline & Born Outside UK & Economically inactive/ looking after family/home \\
\hline & Population Density & \\
\hline & No Central Heating & \\
\hline
\end{tabular}




\title{
Table 5.3 OAC cluster profiles, supergroup level ${ }^{1}$
}

\author{
People per Room \\ Public transport to work \\ Students \\ Unemployment
}

Note: Please see page xii for symbols and conventions used in this report.

1 Adapted from Vickers, D.,Rees,P. \& Birkin,M (2005) Creating the national classification of Census output areas: data, methods and results. 
Table 5.4 Average weekly household expenditure by OAC supergroup, 2009

based on weighted data and including children's expenditure

\begin{tabular}{|c|c|c|c|c|c|c|c|c|c|}
\hline & & 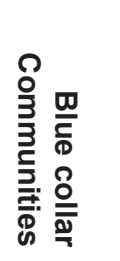 & 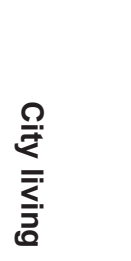 & $\begin{array}{l}8 \\
\stackrel{2}{c} \\
\frac{5}{2} \\
\frac{1}{2} \\
\frac{0}{0} \\
\frac{0}{10}\end{array}$ & 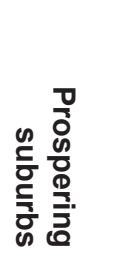 & 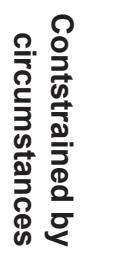 & 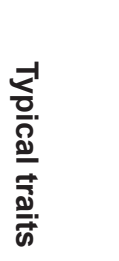 & 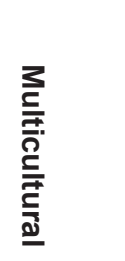 & \\
\hline & & $\begin{array}{r}\text { OAC } \\
\text { Super- } \\
\text { group } \\
1\end{array}$ & $\begin{array}{r}\text { OAC } \\
\text { Super- } \\
\text { group } \\
2\end{array}$ & $\begin{array}{r}\text { OAC } \\
\text { Super- } \\
\text { group } \\
3\end{array}$ & $\begin{array}{r}\text { OAC } \\
\text { Super- } \\
\text { group } \\
4\end{array}$ & $\begin{array}{r}\text { OAC } \\
\text { Super- } \\
\text { group } \\
5\end{array}$ & $\begin{array}{r}\text { OAC } \\
\text { Super- } \\
\text { group } \\
6\end{array}$ & $\begin{array}{r}\text { OAC } \\
\text { Super- } \\
\text { group } \\
7\end{array}$ & $\begin{array}{r}\text { All } \\
\text { house- } \\
\text { holds }\end{array}$ \\
\hline \multicolumn{2}{|c|}{ Weighted number of households (thousands) } & 4,330 & 1,600 & 3,330 & 5,720 & 2,980 & 5,240 & 2,790 & 25,980 \\
\hline \multicolumn{2}{|c|}{ Total number of households in sample } & 1030 & 290 & 850 & 1,360 & 670 & 1,130 & 490 & 5,830 \\
\hline \multicolumn{2}{|c|}{ Total number of persons in sample } & 2,560 & 580 & 2,060 & 3,350 & 1,340 & 2,620 & 1,240 & 13,740 \\
\hline \multicolumn{2}{|c|}{ Total number of adults in sample } & 1,860 & 480 & 1,670 & 2,660 & 1,060 & 2,030 & 880 & 10,650 \\
\hline \multicolumn{2}{|c|}{$\begin{array}{l}\text { Weighted average number of persons per } \\
\text { household }\end{array}$} & 2.5 & 2.0 & 2.4 & 2.4 & 2.0 & 2.3 & 2.6 & 2.3 \\
\hline \multicolumn{2}{|c|}{ Commodity or service } & \multicolumn{8}{|c|}{ Average weekly household expenditure $(£)$} \\
\hline 1 & Food \& non-alcoholic drinks & 50.20 & 47.40 & 56.80 & 60.10 & 41.50 & 51.50 & 49.00 & 52.20 \\
\hline 2 & Alcoholic drinks, tobacco \& narcotics & 12.30 & 11.00 & 12.30 & 10.70 & 11.10 & 11.10 & 9.40 & 11.20 \\
\hline 3 & Clothing \& footwear & 17.40 & 24.80 & 21.90 & 25.20 & 14.40 & 20.90 & 21.40 & 20.90 \\
\hline 4 & Housing (net) ${ }^{1}$, fuel \& power & 48.40 & 95.60 & 56.10 & 50.90 & 49.90 & 54.50 & 77.00 & 57.30 \\
\hline 5 & Household goods \& services & 21.80 & 25.90 & 32.40 & 35.50 & 21.00 & 28.30 & 24.60 & 27.90 \\
\hline 6 & Health & 2.50 & 6.20 & 7.90 & 7.50 & 3.40 & 4.70 & 4.50 & 5.30 \\
\hline 7 & Transport & 45.60 & 57.30 & 72.20 & 77.90 & 32.70 & 58.60 & 49.70 & 58.40 \\
\hline 8 & Communication & 10.90 & 13.60 & 12.00 & 12.20 & 8.80 & 11.70 & 13.20 & 11.70 \\
\hline 9 & Recreation \& culture & 44.40 & 55.20 & 71.80 & 76.40 & 39.40 & 59.70 & 41.90 & 57.90 \\
\hline 10 & Education & 1.10 & 14.40 & 8.00 & 7.30 & 2.30 & 5.00 & 18.70 & 7.00 \\
\hline 11 & Restaurants \& hotels & 28.50 & 62.20 & 40.10 & 47.00 & 22.80 & 37.90 & 37.70 & 38.40 \\
\hline 12 & Miscellaneous goods \& services & 26.50 & 44.30 & 42.20 & 43.50 & 22.00 & 36.20 & 29.00 & 35.00 \\
\hline $1-12$ & All expenditure groups & 309.60 & 457.90 & 433.70 & 454.10 & 269.20 & 380.00 & 376.10 & 383.10 \\
\hline
\end{tabular}

Note: Please see page xiii for Symbols and conventions used in this report.

1 Excluding mortgage interest payments, council tax and Northern Ireland rates.

ONS, Family Spending 2009, (c) Crown copyright 2010 


\section{Table 5.5 Average weekly household expenditure by OAC group, 2009} based on weighted data and including children's expenditure

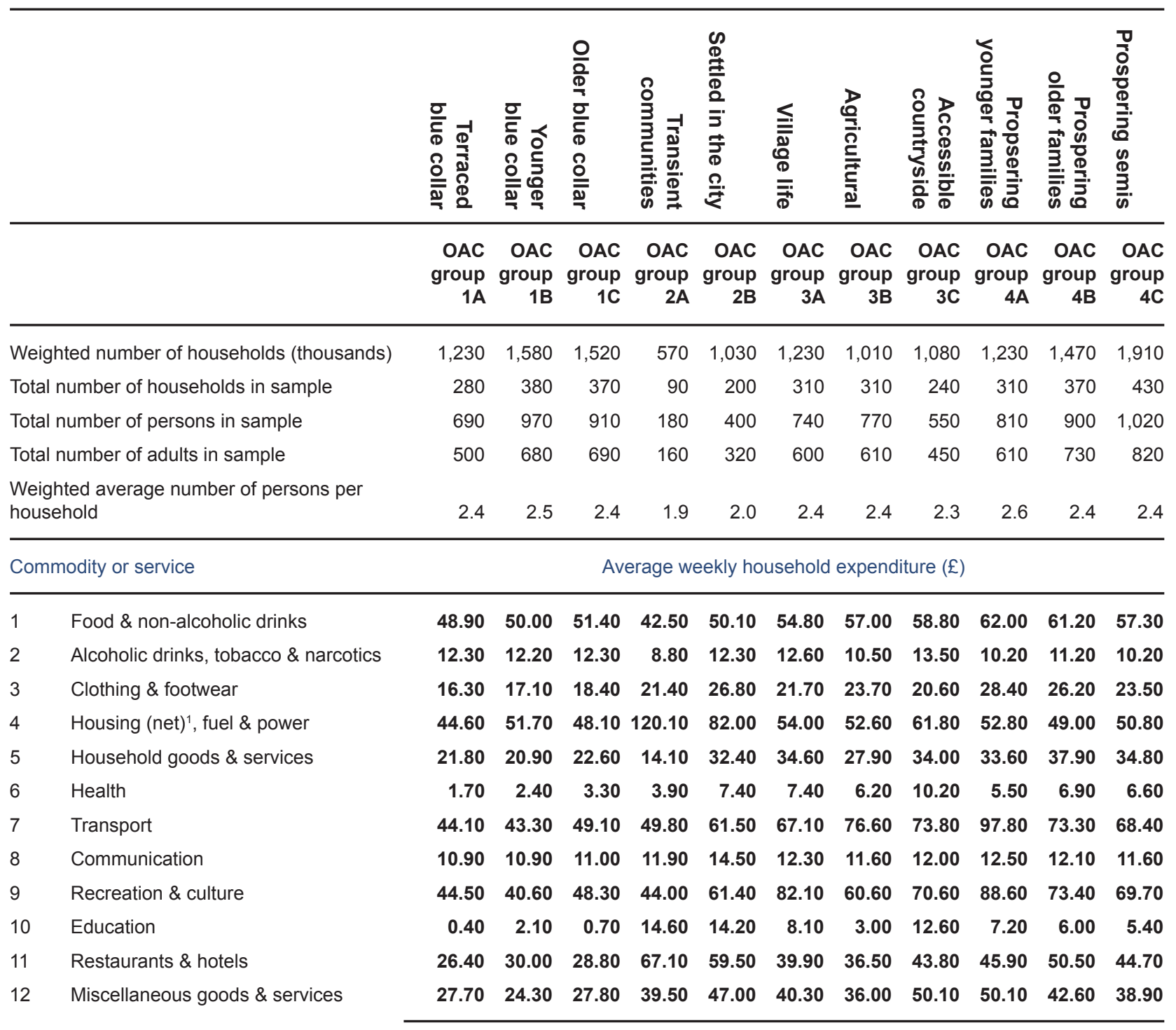

1-12 All expenditure groups

$299.60 \quad 305.50321 .80 \quad 437.70469 .00 \quad 434.90 \quad 402.20461 .80494 .50 \quad 450.30422 .00$

Note: Please see page xiii for Symbols and conventions used in this report.

1 Excluding mortgage interest payments, council tax and Northern Ireland rates.

ONS, Family Spending 2009, ( C Crown copyright 2010 
Table 5.5 Average weekly household expenditure by OAC group, 2009 (cont.)

based on weighted data and including children's expenditure

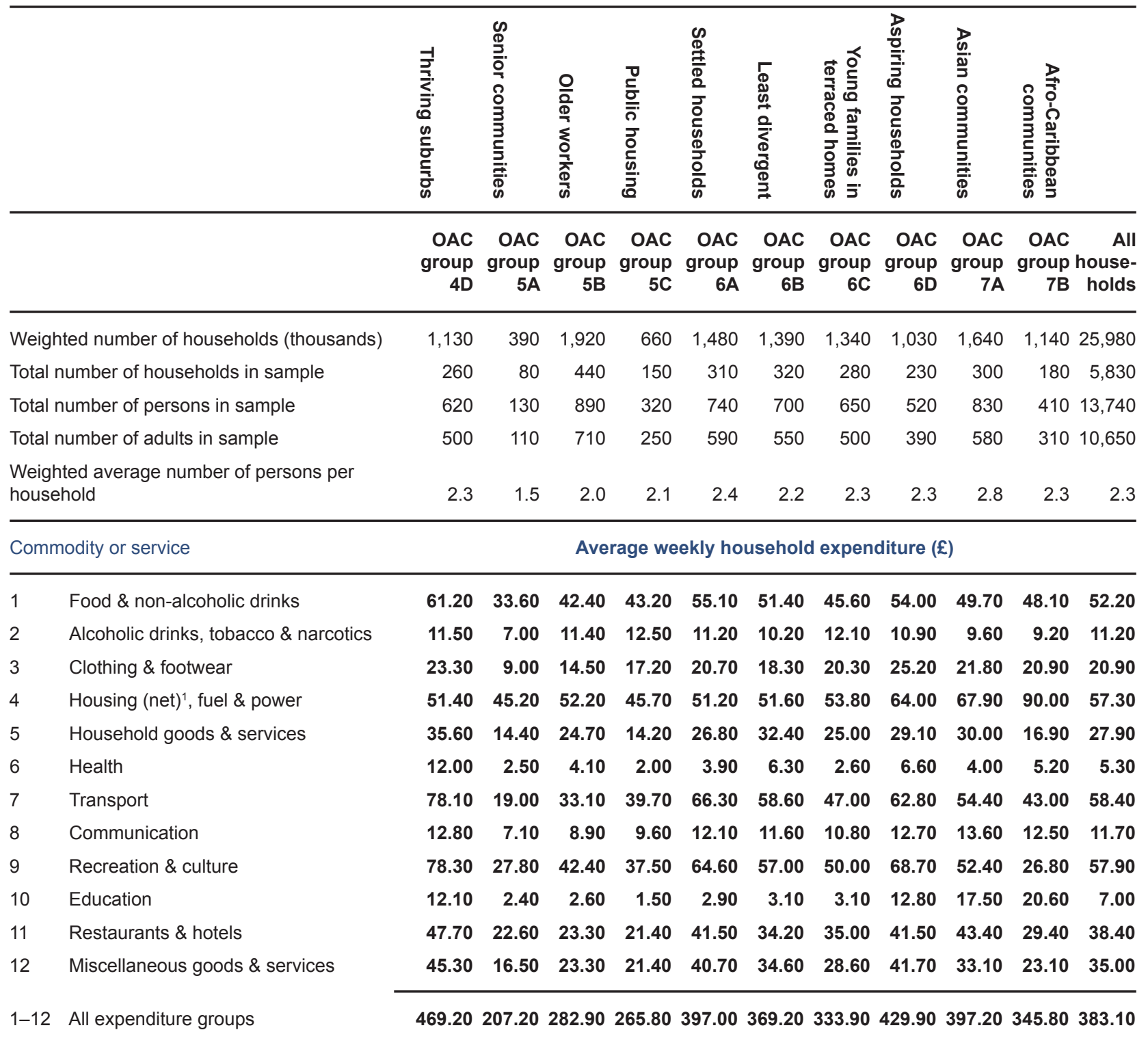

Note: Please see page xiii for Symbols and conventions used in this report.

1 Excluding mortgage interest payments, council tax and Northern Ireland Rates.

ONS, Family Spending 2009, ㄷ Crown copyright 2010 


\section{Table 5.6 Average gross normal weekly household income by OAC supergroup, 2009}

based on weighted data

\begin{tabular}{|c|c|c|c|c|c|c|c|c|}
\hline & 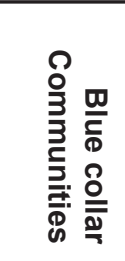 & 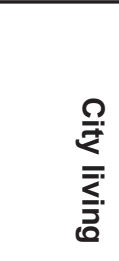 & $\begin{array}{l}2 \\
\stackrel{2}{5} \\
\frac{2}{2} \\
\frac{5}{2} \\
\frac{0}{2} \\
\frac{2}{10}\end{array}$ & 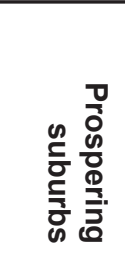 & 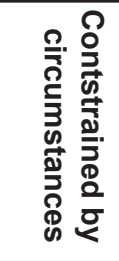 & 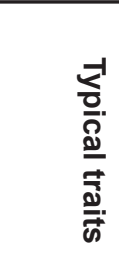 & 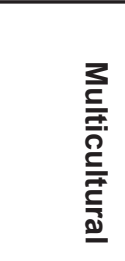 & \\
\hline & $\begin{array}{r}\text { OAC } \\
\text { Super- } \\
\text { group } \\
1\end{array}$ & $\begin{array}{r}\text { OAC } \\
\text { Super- } \\
\text { group } \\
2\end{array}$ & $\begin{array}{r}\text { OAC } \\
\text { Super- } \\
\text { group } \\
3\end{array}$ & $\begin{array}{r}\text { OAC } \\
\text { Super- } \\
\text { group } \\
4\end{array}$ & $\begin{array}{r}\text { OAC } \\
\text { Super- } \\
\text { group } \\
5\end{array}$ & $\begin{array}{r}\text { OAC } \\
\text { Super- } \\
\text { group } \\
6\end{array}$ & $\begin{array}{r}\text { OAC } \\
\text { Super- } \\
\text { group } \\
7\end{array}$ & $\begin{array}{r}\text { All } \\
\text { house- } \\
\text { holds }\end{array}$ \\
\hline Weighted number of households (thousands) & 4,330 & 1,600 & 3,330 & 5,720 & 2,980 & 5,240 & 2,790 & 25,980 \\
\hline Total number of households in sample & 1,030 & 290 & 850 & 1,360 & 670 & 1,130 & 490 & 5,830 \\
\hline Total number of persons in sample & 2,560 & 580 & 2,060 & 3,350 & 1,340 & 2,620 & 1,240 & 13,740 \\
\hline Total number of adults in sample & 1,860 & 480 & 1,670 & 2,660 & 1,060 & 2,030 & 880 & 10,650 \\
\hline $\begin{array}{l}\text { Weighted average number of persons per } \\
\text { household }\end{array}$ & 2.5 & 2.0 & 2.4 & 2.4 & 2.0 & 2.3 & 2.6 & 2.3 \\
\hline Gross normal weekly household income & 493.00 & 936.70 & 775.90 & 844.80 & 430.70 & 703.00 & 616.90 & 682.60 \\
\hline
\end{tabular}

Note: Please see page xiii for Symbols and conventions used in this report.

ONS, Family Spending 2009, (c Crown copyright 2010 